\title{
DOCUMENTOS
}

\section{Acerca de los tambores y pífanos en el Real Ejército de Chiloé}

\author{
About the Fife-Players and Drummers in the \\ Royal Army of Chiloé
}

\author{
por \\ Pablo A. Pérez \\ Asociación Española de Historia Militar, España \\ pa.perez1@gmail.com
}

Este documento presenta datos recabados acerca de los tambores y pífanos del Real Ejército de Chiloé (sur de Chile) durante el siglo XVIII y el período 1814-1817, así como otros ejemplos de personas relacionadas con la música por medio de referencias documentales inéditas. De esta manera, se realiza un aporte a la historiografía musical en Chiloé desde una perspectiva documental que hasta ahora no ha sido suficientemente tomada en cuenta en los estudios acerca de la cultura musical chilota.

Palabras clave: Chiloé, Ejército Real, tambor, pífano, música, genealogía, historia.

This document presents collected data about the drums and fifes of the Royal Army of Chiloé (south of Chile) during the 18th century and the period 1814-1817, as well as other examples of people related to music through unpublished documentary references are given. This way, it contributes to musical historiography of Chiloé from a documental viewpoint that until now has not been considered in studies about Chiloé's music culture.

Keywords: Chiloé, Royal Army, drummer, fife, music, genealogy, history.

\section{INTRODUCCIÓN}

La música en Chiloé ha originado material de estudio que aún promete más investigaciones: Cavada (1914) transcribió el cántico llamado "de los Ángeles" y dedicó todo un capítulo a los bailes populares; mientras que Eugenio Pereira Salas (1941) estudió danzas y cantos de Chiloé; Marco Antonio León León (1999) estudió con erudición los ritos mortuorios (entre ellos los velorios y novenarios) y recientemente Garrido, Bendrup y Hayward (2019), además de consideraciones históricas, estudian las expresiones de música contemporánea e incluso resumen la presencia e importancia de los folcloristas del tiempo actual.

Diversos viajeros y visitantes de Chiloél han notado la afinidad y la sensibilidad del habitante de Chiloé hacia el fenómeno musical, cosa que al autor del presente documento no deja de extrañar, si

\footnotetext{
${ }^{1}$ Por ejemplo, Byron 1768, Morell 1832 o Blanckley 1834, que serán citados más adelante.
} 
se tiene en cuenta el aislamiento y la rusticidad general en la que se hallaba confinada la provincia ${ }^{2}$ Esta paradoja expone quizá peculiares sensibilidades del isleño.

Aunque la música es un producto cultural y, en el caso de Chiloé, una marca de identidad, la historiografía regional ha pasado algunos datos por alto, especialmente en lo que respecta a las personas directamente vinculadas con la música en tiempos pasados. Personas excluidas del discurso de la historia formal, pero que con toda seguridad son las responsables de que la práctica musical existiera en este lugar ${ }^{3}$.

Este documento se propone presentar generalidades en torno a la música en Chiloé, con particular atención en los tambores y pífanos de los Reales Ejércitos durante los siglos XVIII y XIX, dentro del marco de una línea investigativa de carácter personal, de mayor alcance, y vinculada a salvaguardar patrimonio histórico y genealógico de la región.

\section{LA MÚSICA SACRA, LA MÚSICA PROFANA E INSTRUMENTAL EN CHILOÉ}

Si la cultura tradicional en Chiloé es un resultado de la unión de elementos indígenas y europeos, se esperaría encontrar rastros de ello en su música. Sin embargo, las referencias a la expresión musical de las etnias aborígenes en particular son prácticamente inexistentes ${ }^{4}$.

Resulta de sumo interés que exista un exclusivo repertorio de música sacra como cantos de procesiones o rosarios cantados (Lavín 1952: 76; Quevedo 2006), aunque también debe destacarse la existencia de romances cantados (Pizarro 1991), y ritmos como la sirilla, el siquimiriquí, el pasacalle (Cavada 1914: 163-175), las olas, el chocolate, el llanto (Pereira Salas 1941: 235-237), entre otras. Hubo más expresiones musicales como el fandango, danza característica del siglo XVIII en Chile, que es citada como conservada especialmente en Chiloé (Pereira Salas 1941: 208).

La práctica de salomar (Cavada 1914: 406) igualmente puede tener un origen en la fusión cultural hispana e indígena, de forma que, mientras la península ibérica era la heredera de la celeusma romana, en Chiloé se puede rastrear hasta el pur-ru, con el significado de "himnos de alegría en medio de los trabajos" (Medina 1882: 355). En el análisis de la génesis del cancionero criollo, el aporte indígena se menciona proyectado y conservado en festividades de religiosidad popular en Chiloé (Pereira Salas 1941: 170).

En 1973 el folclorista conocido como Oreste Plath (1973: 49) escribió que en las fiestas populares religiosas de Chiloé participaban conjuntos formados por violines, pitos, flautas, tambores, cajas, triángulos, etc.; y puntualizó el uso de los rabeles (llamados popularmente "rabiosos"), los "barraquitos" (antiguos violines con tripas de carnero) y las guitarras de fabricación casera (llamadas "vihuelas").

Lo cierto es que, de la mano jesuítica, la religión parece haber dejado gran influencia en la génesis y supervivencia de la música de Chiloé (Lavín 1952: 77; Rondón Sepúlveda 1997: 7, 30-32). Esto es de una lógica natural porque, en sus inicios, las fiestas religiosas (del mismo modo que las celebraciones civiles) debían ser normal ocasión para la ejecución musical. Se sabe, por ejemplo, que en 1610 el padre Diego de Torres había enseñado ya a los indígenas a cantar unas canciones de la doctrina en su

2 El asentamiento y población se hizo en esta provincia en comunidades locales (generalmente costeras), y se advierte desde los primeros tiempos una modalidad de las rutas de comunicación acuática (Rondón Sepúlveda 2009: 531). Esta situación podía prolongar las visitas misionales a las numerosas capillas dispersas en el archipiélago, a causa del clima muchas veces adverso, hecho acrecentado por la escasez de religiosos empleados en la provincia (Urbina Burgos 1983: 166-173). La pobreza y la escasez de moneda, de víveres y todo tipo de insumos (hierro, papel, etc.) fue tan característica de Chiloé durante los primeros siglos desde su fundación, como la riqueza de su fauna marina (Urbina Burgos 1983: 14, 50-51, 100, 139).

3 Es decir, no se entregan, por ejemplo, datos acerca de la identidad de los ejecutantes de los instrumentos musicales en las iglesias, ni de los constructores de instrumentos musicales, etcétera.

4 A nivel general, se acepta que las sociedades "primitivas" que creían en la influencia de ánimas o espíritus gustaban de bailes y música (Latcham 1924: 246-247). Para Chiloé en concreto, en un cuestionario de 1789 acerca de su población indígena atribuido a Antonio Pineda, se especifica que "Usan de la musica y la conozen: tienen musica de Guerra con clarines dados de Valdivia. Bailan y cantan” (González Montero de Espinosa 1992: 151-153). 
lengua (Rondón Sepúlveda 2009: 285). La música de estas islas, elemento festivo como doctrinario, fue un aspecto que los jesuitas quisieron mejorar. En 1636, por ejemplo, la orden trajo al hermano Luis Berger (conocido pintor, músico, platero y médico) desde las reducciones del Paraguay, para enseñar música, cantos sagrados y formar coros en Chiloé (González Coll 1999: 261; Moreno Jeria 2007: 278).

El padre Juan de Olivares (1874: 364) señala entre 1712-1720 que en Chiloé:

está fundada la ciudad de Castro, de donde son vecinos todos los españoles que habitan en este archipiélago, aunque no habitan en ella, que cada uno asiste donde tiene sus tierras i ganados i sementeras. Júntanse por la semana santa en la ciudad a cumplir con la iglesia, las pascuas de Navidad, para elegir su cabildo de alcaldes i rejidores, que todos los años se crean nuevos i por la fiesta de Santiago apóstol, a quien tienen por patron, i celebran con mucho regocijo, sacando el estandarte real, muestran gallardías en las carreras i manejos de los caballos. Con esta ocasion de juntarse a celebrar el santo apóstol, dura su mansion en la ciudad hasta pasada la fiesta de nuestro padre san Ignacio; i se celebra la fiesta de nuestro padre en concurso de toda la jente i vecinos de las islas.

Las referencias documentales específicas a personajes relacionados con el mundo musical son muy escasas. Tal vez, en este sentido, la primera mención concreta a una persona dedicada a la música en Chiloé sea la de Luis Ruiz (nacido en la ciudad de Castro; viudo de Bartola Gallegos), quien se casó el 16 de agosto de 1769 con Josefa Ojeda (nacida en Nercón; hija legítima de Santiago Ojeda y de Josefa Águila), ocasión en que consta que "fue Casado de Carid. ${ }^{\mathrm{d}}$ por servir ala Iglecia de tocador" (LMC4, fojas 48v y 49). La cita no especifica qué instrumento musical tocaba, lo que acaso sería demasiado pedir para la mención de un testigo de matrimonio.

También unos años más tarde, al casarse José Vidal con Ignacia Águila el 16 de septiembre de 1774, Martín Segovia (sin duda hijo legítimo de Luis de Segovia y de María Barrientos, y casado en 1730 con María Muñoz de Alderete), cuyo nombre aparece precedido por un ilustrativo "el Cantor" (LMC4, fojas 81), testifica para proveer información. Nada más se lee acerca de este intérprete en el plano de la música, pero la cita es muy explícita acerca de su profesión.

Los cargos seculares de fiscal, sotafiscal y patrón correspondían a vecinos laicos que tenían a su cargo la comunidad parroquial en ausencia del cura o que estaban encargados de ciertas tareas específicas en la iglesia y tuvieron importancia capital en la preservación de las prácticas musicales ${ }^{5}$. Pero nada hay mejor que un ejemplo: en el territorio de la actual comuna de Dalcahue, hay noticia de una persona llamada Jacinto Pérez (también D. ${ }^{\mathrm{n}}$ Jacinto Pérez en dos ocasiones), quien fue patrón y músico de la iglesia parroquial de Tenaún ${ }^{6}$. Consta asentado hasta 1832 en Quilquico, mientras

5 Refiriéndose al cargo dice un autor: "En tiempos de los jesuitas tenía que ser buen cantor para mantener la tradición de la música sagrada” (Hanisch 1982: 14, 252-253). El religioso Justo Donoso es explícito en este sentido, en su relato del festejo de fiestas patronales el 13 de marzo de 1851: "Curiosos son todos los pormenores del ceremonial en tales ocasiones; pero lo que es muy digno de llamar la atención i no puede pasarse en silencio, es la destreza y señalado gusto que se advierte en el canto i la música, la variedad de misas que los cantores saben oficiar i la regular corrección con que leen el latín. Los fiscales i sotas son por lo común los cantores de cada capilla, i tienen gran cuidado en enseñar a sus hijos el canto i la lectura del latín que ellos también aprendieron de sus padres. Los instrumentos que acompañan el canto son el violín, la flauta i la guitarra i los que lo tocan (de cierto con hábil destreza) no han tenido más principio ni otro maestro que su atinado y exquisito oído. En las festividades de que hablo, el cura canta siempre las vísperas alternando con los fiscales i sota-fiscales, i el día siguiente celebra la misa solemne con que los cantores i músicos apuran su maestría en extremo agradable. En una de las mismas solemnes a que asistí en la visita oficiaron en el coro una linda misa cinco o seis cantores, acompañados de seis violines, dos flautas i una bandurria, instrumento parecido al violín pero de tres cuerdas i se toca con una pluma del grueso i cortada a la manera de las que sirven para escribir. Parecíame el coro harto preferible al de la capilla de la Catedral de Santiago en los días de gran solemnidad" (Retamal 1983: 182-183).

6 Nació en 1790 en Yutuy y falleció a los setenta y cinco años en 1865 en Tenaún, siendo hijo legítimo de Mariano Pérez y de María Serafina Calisto, y contrajo nupcias el 27 de agosto de 1810 en Castro (LMC7, fojas 120) con María Juana de Aguilar (hija legítima de Juan Ignacio Aguilar y de María 
que para 1838 ya figura junto a su esposa como padrino de casamiento en Tenaún (LMT1, fojas 5, $\mathrm{N}^{0}$ 33), donde debió migrar la familia. El matrimonio de Jacinto Pérez y María Juana de Aguilar dejó descendencia de nueve hijos, y dos de ellos fueron patronos de iglesia, mientras otro también ofició de sotafiscal de la misma iglesia de Tenaún.

Los cantores campesinos parecen haber tenido igual importancia como transmisores de la tradición musical profana. Por desgracia, y como en toda sociedad donde la oralidad es muy importante, las referencias escritas son prácticamente inexistentes ${ }^{7}$.

En cuanto a los instrumentos musicales, hay constancia de cordófonos frotados (viola da gamba o rabel) en el primer cuarto del siglo XVII, campanas y órganos en las iglesias (Rondón Sepúlveda 1997: 29). Mientras en el siglo XVIII, en el inventario de la Compañía de Jesús en Castro al momento de su expulsión (1767), figuran un modesto violín y dos guitarras (Rondón Sepúlveda 1997: 30). El navegante John Byron, justamente de paso por estas fechas, indica "Las mujeres tienen tez fina; y muchas de ellas son muy hermosas; tienen buenas voces, y pueden rasguear un poco la guitarra" $(1768: 190)^{8}$.

A poco de haberse incorporado el territorio de Chiloé al gobierno republicano (1826), comenta un marino y explorador estadounidense:

La diversión sedentaria de los chilotes consiste principalmente en música y juegos de cartas; y este es particularmente el caso en San Carlos [de Ancud]. Su instrumento favorito es la guitarra española, en la que casi todas las mujeres tocan con un efecto agradable, acompañadas con la voz, algunas de ellas las más dulces que he escuchado. Ellas también tocan el harpa, la espineta, el clavicordio y el pianoforte. Los caballeros tocan la flauta y el clarinete, y los dos sexos danzan con gracia exquisita, acompañándose ambos de la debida proporción de gracia castellana. Sus principales danzas son los minuets, bailes largos, cotillons y el celebrado fandango. Este último es un baile muy fascinante, ejecutado por dos personas; comúnmente por una dama o un caballero, a veces por dos damas.

Se introducen mesas de cartas en todas sus fiestas, en las que el caballero juega solo, mientras las damas los divierten con canciones acompañadas de la guitarra o el harpa. Los caballeros que no juegan cartas tienen el privilegio de unirse a las damas, un privilegio que nunca perdí ni descuidé (Morrell 1832: 166) ${ }^{9}$.

Este registro tiene un valor interesante desde el punto de vista musicológico, porque expone información de un conjunto de instrumentos musicales en uso en aquel entonces (harpa, espineta,

Agustina Alvarado). Habiendo recibido los auxilios de la religión, y sin testar por no tener bienes de que disponer, se le hicieron sufragios de entierro mayor al momento de su sepultura, acaecida el 8 de mayo de 1865 en el panteón de Tenaún (LDT3, fojas 2).

7 La excepción debe hacerse para el tiempo contemporáneo, en que autores han dedicado un esfuerzo a plasmar las personalidades relacionadas a la música popular de Chiloé, desde cantores populares hasta grupos musicales (Garrido, Bendrup y Hayward 2019: 29-74) e incluso discografía (Garrido, Bendrup y Hayward 2019: 117).

8 Traducción propia. Texto original: The women have fine complexions, and many of them are very handsome; they have good voices, and can strum a little upon the guittar.

9 Texto original: The sedentary amusement of the Chiloeans principally consist of music and card-playing; and this is peculiarly the case at St. Carlos. Their favourite instrument is the Spanish guitar, on which almost every female performs with pleasing effect, accompanied with the voice-some of them the sweetest I ever heard. They also play the harp, spinnet, hapsichord, and piano-forte. The gentlemen play the flute and clarionet, and both sexes dance with exquisite grace, accompained with a due proportion of Castilian dignity. Their principal dances are minuets, long dance, cotillions, and the celebrated fandango. The latter is a very fascinating dance, performed by two persons; commonly by a lady or gentleman, sometimes by two ladies.

Card-tables are introduced at all their parties, at which the gentleman play by themselves, while the ladies amuse them with songs, accompained by the guitar or harp. Such gentlemen as do not fancy cards have the privilege of joining the ladies - a privilege which I never forfeited or neglect. 
clarinete, guitarra, clave y piano ${ }^{10}$ ), destacando como ejecutantes a las mujeres. La impresión que suscita el testimonio, es que debió suceder en algún lugar más bien acomodado, y seguramente no en el más humilde de los hogares.

Un militar inglés aporta unos admirados comentarios a la danza, música y canto en Chiloé, a solo dos años después de la referencia anterior. Sus palabras, alabanza a una sociedad casi idílica, también merecen una transcripción literal:

Los habitantes son muy alegres y parecen ser la raza más feliz que he visto. Sus diversiones, grandes y chicas, consisten en bailar al son de la guitarra, siempre acompañados de canto; y con chicha y sidra de manzanas, bailarán por siempre. Las mujeres, casi sin excepción, cantan bien; sus figuras también son buenas y, acostumbradas a bailar desde su infancia, no desacreditarían el mejor salón de baile europeo. Todos son apasionados por la música; y fue agradable escuchar algunas de las mejores óperas de Rossini cantadas para pianos, de los cuales había varias en San Carlos, y bien interpretadas, tanto vocal como instrumentalmente (Blanckley 1834: 357)11.

Nuevamente destacan las mujeres en las impresiones del británico, mientras entre los instrumentos musicales, el piano y la guitarra acaparan la atención del cronista.

Resulta interesante en las tres citas anteriores (que suceden entre 1768 y 1834) la insistencia en ponderar las cualidades musicales (de canto y de interpretación) y dancísticas de las mujeres, hasta hacerlas extensivas de forma genérica a la mayoría de ellas. Quizás, la presencia de instrumentos como pianos, claves, espinetas, tenga que ver con el surgimiento de la Sociedad Musical de San Carlos (Garrido, Bendrup y Hayward 2019: 34).

Algunos años más tarde se encuentra una mención a la música no tan halagüeña como las anteriores. El músico, compositor y político José Zapiola relata cómo, llegado a Castro en 1850 al momento de su deportación, se encuentra con que "Se celebraba en esos días la Pascua de Navidad, ¡y toda música de aquella fiesta tan popular se reducía a una especie de viola horriblemente tocada!" (Zapiola 1974: 59). Se refiere sin duda, al rabel ${ }^{12}$, verdadera herencia mozárabe, pero que puede desagradar a un oído falto de costumbre.

Una treintena de años más adelante, consta haber ocho músicos hombres en 1865 en Chiloé, todos residentes en el departamento de Ancud (Gobierno de Chile 1866: 10-11), uno de estos era alemán (Gobierno de Chile 1866: 15). Diez años después, en cambio, se encuentra censada la increíble cantidad de dieciséis músicos hombres, todos siempre en el departamento de Ancud, aunque ninguno de ellos figura detentando alguna nacionalidad extranjera, ni siquiera la alemana (Gobierno de Chile 1876: 31, 38). En 1885 quedan seis músicos hombres en el departamento de Ancud y un hombre músico en el departamento de Quinchao (Gobierno de Chile 1890: 10-11).

También hay informaciones referidas a otros músicos radicados en la zona de Ancud, como Nicolás Soto Vera (hijo de Pascual Soto y de María Vera), casado el 18 de febrero de 1888 en Ancud ${ }^{13}$; o Manuel Jesús Escalona Jiménez (hijo de José María Escalona y de Santos Jiménez), casado el 8 de

10 Este instrumento tuvo su aparición en Chiloé en 1800 (Barría Casanova 2014: 38).

11 Texto original: The inhabitants are very cheerful, and appear the happiest race I ever beheld. Their amusements, high and low, consist in dancing to the guitar, always accompanied by the voice; and, with chich a and cider from apples, they will dance for ever. The females, almost without exception, sing well; their figures also are good, and, accustomed to dance from their infancy, they would not discredit the best European ball-room. All are passionately attached to music; and it was pleasing to hear some of Rossini's best operas sung to pianos, of which they were several in St. Carlos, and well performed, both vocally and instrumentally.

12 Acerca del origen de este instrumento en el elenco de instrumentos de tiempo hispánico en Chile, si bien se ha sugerido que esté relacionado con el trabajo del jesuita Berger (Rondón Sepúlveda 2009: 306), también podría estar relacionado con la presencia de esclavos blancos o moriscos, que en la primera época de la conquista peruana fueron mujeres principalmente (Lockhart 1952: 251-252). Entre 1532 y 1549 llegaron a Perú por lo menos unas trescientas mujeres calificadas de moriscas (Lockhart 1952: 251-252). Además, Perú, en comparación con Santiago de Chile, mantuvo mucha mayor relación con Chiloé (Pérez 2019b: 253-254).

13 Registro Civil de Ancud. Casamientos del año 1888, Libro No ${ }^{\circ}$, Asiento $N^{\circ} 8$. 
abril de 1888 en Ancud ${ }^{14}$. Ambos constan como chilenos, y se da la casualidad de que contrajeron matrimonio en el mismo año y localidad.

\section{LA MÚSICA MILITAR EN CHILOÉ EN LOS SIGLOS XVIII Y COMIENZOS DEL XIX}

De la música militar en los siglos de dominio hispánico es poco y nada lo que queda documentado. La situación militar en la antigua provincia de Chiloé dejaba bastante que desear, ya en la instrucción de las personas, como en los pertrechos que se recibían, sus sueldos, entre otros. Ninguna evidencia apunta a pensar que la música militar sería un ámbito privilegiado; debía de estar reducida a una expresión mínima, con trompetas, tambores y pífanos. Aquí se reseñarán las informaciones conocidas acerca de este tema.

François-Alexandre Aubert de la Chenaye des Bois fue un escritor y compilador francés de inicios del siglo XVIII que, en su Dictionnaire militaire ou recueil alphabétique de tous les termes propres à l'art de la guerre (1742), ha dejado sendas definiciones para los dos términos que dan origen al título de este documento. Por la calidad y cantidad de informaciones que contiene, conviene transcribir estas definiciones para conocimiento de la comunidad lectora, según la traducción al castellano hecha por Raimundo Sanz de la obra de Chenaye des Bois en 1749:

- TAMBOR: ò Caxa de guerra, es un instrumento menos antiguo que la Trompeta. No se lee que los Romanos se ayan servido de èl, en las guerras. El parche con que tocan las baquetas; siempre ha sido de una piel tersa, y tendida, y ha mucho tiempo que se usa de la de carnero. Al Tambor llaman Caxa, porque es de madera, aunque ha sido alguna vez de Cobre, ò de Laton, como los Cuerpos de Timbales de oy. El Tambor es para la Infanteria, y Dragones, como la Trompeta para la Cavalleria. Los toques del Tambor son tan diferentes, como los diversos movimientos, y reenquentros. Dicese tocar la Diana, la Generala, \&c. (Sanz 1749: 399-400).

- TAMBOR: es un Hombre destinado para tocar el Tambor, ò Caxa, en el servicio; sea para advertir la Tropa en diferentes ocasiones del Servicio, ò para proponer alguna cosa al Enemigo, tocando la Llamada. Cada Regimiento de Infanteria tiene un Tambor Mayor, y cada Compañia tiene el suyo particular. Dicese, tocar la Marcha para advertir à un Cuerpo de Infanteria, que tiene orden de marchar; pero si esta orden se estiende sobre toda la del Exercito, se hace tocar la Generala. Tocar la Assamblea, es advertir à los Soldados que vayan à sus Banderas, y quando las Tropas empiezan à marchar, se toca la Marcha; quando tocan à Degüello, ò à Guerra, es quando se và contra el Enemigo; el toque que se hace despues de una accion, es la Retirada: Tambien se toca en una Guarnicion para hacer retirar a los Soldados à su Quartel. Tocar la Llamada precipitada, es para hacer tomar las Armas con prontitud à los Soldados, quando inopinadamente passa alguna persona de calidad delante del Cuerpo de Guardia, y que es necessario hacerle los honores. En una Guarnicion se toca la Diana à la aurora, ò romper del dia; pero quando se hace un Sitio, como la Infanteria monta la Guardia de Trinchera, es la que rompe el nombre con la Diana à la aurora, y à este toque siguen las primeras descargas de Cañones, que la obscuridad de la noche havia interrumpido, por la impossibilidad de apuntar las piezas con acierto, à los Trabajos de los Sitiados. Quando un Batallon està sobre las Armas, los Tambores estàn en las Alas, y quando desfilan, unos estàn en la Vanguardia, otros en las Divisiones, y otros en la Retaguardia. (Sanz 1749: 400-401).

- PÍFANO: es una especie de flauta, que està hueca, con un orden de agugeros, para proporcionar la voz. Este se emboca en el primero, y dà un eco muy agudo. Los Suìzos llevaron este instrumento à Francia para acompañar la Caxa. En tiempo de Enrique IV. tenian pifanos todas las Compañias de Infanterìa, pero oy es à voluntad de los Regimientos el tenerlos (Sanz 1749: 271).

Eran de variado género las obligaciones de los empleados en el real servicio como tambores. Las reglamentaciones indican, por ejemplo, respecto de la solicitud de licencia para casamientos, que los

14 Registro Civil de Ancud. Casamientos del año 1888, Libro N ${ }^{\circ} 1$, Asiento $N^{\circ} 10$. 
sargentos y cabos de milicias que se casaran sin dicho permiso de sus coroneles serían mortificados con quince días de prisión y depuestos de su empleo, empezando a servir su plaza por diez años. Si el infractor era tambor o pífano, sería castigado con igual arresto, perdería el tiempo servido y empezaría a servir de nuevo por el en que se hubiere empeñado (Colón de Larriátegui 1817: 47). Tampoco podían los tambores tocar canciones ni otra cosa más que la que les correspondiera (Oya 1732: 198). Si bien existen reglamentaciones especialmente dictadas para las milicias americanas (incluso para Chile), no se ha encontrado información referente a si estos tratados de derecho penal escrito que incluían a tambores y pífanos tenían aplicabilidad en los territorios americanos, donde quizá se opondrían al derecho consuetudinario.

También en el plano civil tenían los tambores obligaciones respecto de, por ejemplo, las procesiones religiosas: si la tropa pasaba por alguna de ellas, debía descansar sobre las armas desde su principio hasta el fin, y así también los tambores debían tener la caja al hombro. Del mismo modo, los oficiales debían tener su espada desenvainada, haciendo cortesía al pasar la imagen y, habiéndose acabado la procesión, harían arrimar las armas (Bonaparte 1811: 99).

Finalmente, respecto de los premios de las milicias, de las ordenanzas militares se recoge que:

se socorre tambien à los Soldados invalidos con algun sueldo, en premio de los servicios hechos, y à los actuales manda su Magestad manda se les atienda (siendo benemeritos) en las proposiciones de los empleos vacantes, y se permite, que el Soldado raso, si se huviere distinguido por su valor, y conducta, pueda ascender à los grados de Sargento, Subteniente, y demàs, segun su merito, y aun el Tambor puede ascender à los de la Compañía, y goza de las mismas prerrogativas que los demàs Soldados, à cuyo fin no se le debe sentar la plaza, sino es de edad, y fuerzas, para poder ser Soldado (Oya 1732: 27-28).

En las ordenanzas de 1768 se especificaban las funciones de los tambores mayores, su dependencia jerárquica y sus responsabilidades (Carlos III 1768: I, 257-260). También se explicaban los distintos toques que debían observar los tambores y pífanos, a saber: generala, asamblea, bandera o tropa, marcha, marcha granadera, alto, retreta, bando, llamada, misa, oración, orden, fajina, baqueta, diana y calacuerda (Carlos III 1768: II, 1-5)

En atención a la rebaja de prest ${ }^{15}$ que se propuso a la tropa el 2 de mayo de 1787 , en el virreinato del Río de la Plata se determinó que se diera cuenta de la Real Hacienda para proveer de banderas a los regimientos cada diez años y, por la misma cuenta, se daba cada treinta meses la tercera parte de correaje y gorras de pelo para los granaderos y "Caxas de Guerra con sus Portacaxas, y Cordones, correspondientes para los Tambores” (AGS, SG 7093,23). Las mismas reglamentaciones señalan que el tambor mayor (al igual que los oficiales de caballería y dragones, así como los sargentos) estaban obligados a tener caballo y montura propio costeado de su propio haber, pero los tambores sencillos (al igual que los cabos y soldados) los tenían suministrados por cuenta de la Real Hacienda, para cuyo mantenimiento se estipula un aumento de un tercio (siete reales mensuales) por sobre el haber de la tropa de infantería y dragones. En dicho virreinato, el sueldo de un tambor mayor de infantería era de catorce pesos mensuales, el de un tambor de granaderos diez pesos, el de un tambor de fusileros nueve pesos, el de un pífano primero diez pesos, el de un pífano segundo nueve pesos; el de un tambor mayor de dragones dieciséis pesos, y el de un tambor de dragones y de artillería diez pesos. En el virreinato del Perú en cambio, el tambor mayor cobraba veintiséis pesos mensuales (proponiéndose que cobre tan solo veinticuatro), el tambor de granaderos veinte pesos mensuales (que se proponen reducir a dieciocho), el tambor de los fusileros veinte pesos mensuales (propuestos a diecisiete) y los pífanos primero y segundo cobraban veinte pesos mensuales (propuesto ser ajustado el sueldo de los segundos a dieciocho pesos mensuales).

Lo interesante de este aspecto es que la carrera de la milicia no estaba velada a los tambores y que, como podrá constatarse luego, incluso los sueldos de los tambores eran algo mayores a los de un soldado raso, por lo que puede haber llegado a ser una forma alternativa de ascenso castrense.

$15 \mathrm{El}$ prest era la parte del haber del soldado que el intendente le entregaba en mano semanal o diariamente. El Diccionario de Autoridades, tomo V, de la RAE (1737) reconoce el vocablo pré y lo define así: "El socorro diario que se da a los soldados para su mantenimiento. Es voz modernamente introducida y tomada de los Franceses" (Real Academia Española 1737). 
Lamentablemente la escasez de las informaciones relacionadas con Chiloé (que se restringe a unos pocos años), o de otras noticias complementarias (como fojas de servicio o filiaciones) impiden analizar más detalladamente el tema.

En las tropas no se admitía gente que no fuera blanca, salvo en los tambores que podían ser afrodescendientes (Gómez Pérez 1993: 83). Si bien la presencia africana en el período colonial de Chile fue mucho más abundante de lo que suele creerse ${ }^{16}$, las referencias documentales a personas de este origen en la geografía de Chiloé son escasísimas ${ }^{17}$, por lo que es muy poco probable que hayan existido tambores de esta ascendencia en estas australes latitudes. En cambio, puede ser que indígenas hayan ocupado este cargo. De hecho, se registra al "indio Juan" como tambor de la nómina reglada de Calbuco del año 1696 (Urbina Carrasco 2008: 31).

Una cosa que estimula el interés en este tipo de estudios, es que la calidad de los tambores no parece haber correspondido siempre a personas humildes o de origen poco claro, porque se da el inusual caso de encontrarse a José Hernández, natural de Lima, antes cigarrero, y tambor del Batallón Provincial de Infantería de Milicias de la ciudad de Lima (1799), hijo de don Francisco Hernández y de Hermeregilda Núñez (AGS, SG 7113,15, fojas 118). La distinción honorífica del "don" en el nombre del padre del tambor, alerta sobre el posicionamiento social de esta persona.

Tampoco fueron los tambores siempre naturales de la provincia, ya que también hay constancia de personas de origen español empleados en este oficio, como por ejemplo el tambor catalán Ramón Mars (natural de Barcelona; hijo legítimo de Ramón Mars y de Francisca Olivares), quien fue casado el 28 de enero de 1789 en Valdivia (LMV1, fojas 50) con María Campillo (natural de la plaza de Valdivia; hija legítima de Ana Castro).

\section{ELENCO DE TAMBORES EN CHILOÉ (SIGLO XVIII)}

El empleo en el real servicio de Chiloé como tambor o pífano, es probable que se haya encontrado relacionado con la afinidad de una u otra persona hacia la música (popular o sacra), aparte de las habilidades que haya poseído para poder memorizar e interpretar las melodías castrenses.

16 Entre 1550 y 1615 fueron traídos a Chile más de tres mil esclavos negros. En 1778 en el obispado de Santiago se contaban 23583 negros, zambos y mulatos (Salinas Campos 2000: 65). Ovalle (1646: 339, 348) ya indica que hacia mediados del siglo XVII "han pasado de estos negros muchísimos a Chile". Se llega incluso a consignar que apellidos como Retuerto, Relverto, Cabezudo, Matute, Malverde, etc., eran aquellos que los amos blancos de Lima ponían a sus esclavos negros (Milla Batres 1986: 82). Rondón Sepúlveda 2014 presenta un excelente trabajo acerca de este tema, colaboración que ha de agradecerse especialmente al autor.

17 La primera matrícula de los pobladores de la villa de San Carlos, hecha en 1771, señala ciento diecisiete vecinos, y en ella está documentada la presencia de los siguientes esclavos: cuatro pertenecientes a don Francisco Garay y su esposa doña Cristina Garay, tres a don Gabriel Gómez y su esposa doña Dolores Carrillo, dos a Pedro Mansilla y su esposa doña Josefa Martel, y uno a Alonso Pascual Marín y su esposa Tomasa de la Torre (Urbina Burgos 2013: 2331-234). Es decir, solamente 3,4\% de la población tenía esclavos a título personal, y no hay constancia de ninguno empleado en el ejército.

Los libros parroquiales también han dejado escueta constancia de personas de origen afroamericano. En cuanto a matrimonios hay apenas dos casos registrados: Santiago Barreda (pardo, natural de Santiago), quien se casó en 1741 en Castro con Manuela Cortés (Pérez 2019b: 264); Francisco Vanda (natural de Mozambique), quien se casó en 1809 en Castro con María Juana (natural del Congo) (LMC7, fojas 87v); y Juan del Carmen Manrique (limeño; esclavo) casado en 1815 en Calbuco con Ignacia Esquerra (LMCa3, fojas 170v y 171).

Se consignan además dos bautismos: Francisco (de unos quince años, negro, esclavo), bautizado en 1806 en Castro (LBC12, fojas 58v); María Manuela (de dieciséis años; del Congo), bautizada en 1808 en Castro (LBC12, fojas 109); y Eusebio (de un día, natural de la esclava Brígida), bautizado en 1822 en Castro (LBC15, fojas 155).

Finalmente, se registra también una defunción: Manuela Landayta (de 24 años, de Chillán, esclava de don Sebastián Gómez), en 1820 en Dalcahue (LDC5, fojas 32). 
En las reglamentaciones militares de la tropa reglada de Chiloé, se menciona un tambor para la dotación de la Compañía de Infantería del fuerte de San Miguel de Calbuco, con sueldo de seis pesos y cuatro reales al mes; y un trompeta para la correspondiente a la Compañía de Caballería del fuerte de San Antonio de Chacao, con sueldo de ocho pesos al mes (Pérez 2018b: 58-59).

Acerca de personas con oficio de tambor en el siglo XVIII, muy poco es el material que se ha podido encontrar. Se pueden identificar a las siguientes personas, todas del último tercio de dicho siglo:

- $\quad$ Manuel Hospina (Pérez 2020). Llamado luego don Manuel Ospina. Natural del pueblo de Santa Olaya. Hijo de Pascual Ospina y de Magdalena Gómez. Poseía cinco pies de altura; tenía pelo, cejas y ojos negros, nariz roma y tres cicatrices (una en la frente al ojo izquierdo, otra en el carrillo derecho, y otra abajo de la oreja de este mismo lado); de color trigueño; barbilampiño, en 1772 (AGS, SG 7099,30, fojas 90). Sentó plaza voluntariamente con destino a Chiloé por tiempo de seis años; incorporándoselo como tambor sencillo de la Compañía de Dragones de Chiloé (1 de enero de 1773) (AGS, SG 7099,30, fojas 90); ascendido a tambor mayor (8 de diciembre de 1783), agregado a la Partida de Asamblea (5 de agosto de 1798) (AGS, SG 7133,1, fojas 28v). Testigo de casamiento junto a Juana Gallardo, el 16 de mayo de 1810 en la iglesia parroquial de Castro (LMC7, fojas 114). Con probable descendencia (Pérez 2018a: 478-479).

- $\quad$ Diego Ojeda. Nacido en 1778; natural de Achao (AGS, SG 7110,23, fojas 170) (consta también por natural de Chacao en AGS, SG 7111,17, fojas 60, lo que aparenta ser un error ya que su familia estaba asentada en Achao). Hijo legítimo de Diego Ojeda y de Francisca Torres. De oficio labrador. Poseía cabello y cejas negras, tez morena, ojos pardos, nariz ancha y abultada, y poca barba. Sentó plaza voluntariamente por seis años siendo tambor de milicias (1 de agosto de 1781) (AGS, SG 7111,17, fojas 60). Por haber cumplido tres tiempos de a cinco años, se le asistió con seis reales de plata sobre su prest (15 de julio de 1798 en Madrid) (AGS, SG 7110,23, fojas 170).

- Pedro Juan Barría. Tambor de la Compañía de Artillería de la plaza de Chiloé, presente en las revistas del 5 de abril de 1798 (AGS, SG 7133,1, fojas 24) y 5 de agosto de 1798 (AGS, SG 7133,1, fojas 51).

\section{ELENCO DE TAMBORES Y PÍFANOS EN LAS TROPAS DE CHILOÉ (1814-1817)}

En la Revista de Comisario ${ }^{18}$ consta como oficial agregado en el Batallón de Voluntarios de Castro, con oficio de tambor mayor, Juan Felipe Sicardo (1 de noviembre de 1814; 1 de diciembre de 1814; 2 de enero de 1815; 1 de febrero de 1815), pasado a sargento segundo en la Compañía de Granaderos de dicho Batallón el 27 de febrero de 1815 y constando luego de licencia y en la cárcel (1 de marzo de 1815). Seguidamente, consta por tambor mayor Mateo Hernández (1 de marzo de 1815; 1 de abril de 1815), quizá hijo legítimo de Antonio Hernández y de María Tenorio, habiendo sido bautizado el 1 de noviembre de 1778 .

Entre 1814-1815, un tambor mayor cobraba quince pesos mensuales (igual que un sargento primero), mientras que un tambor cobraba once pesos mensuales (al igual que un cabo segundo) y un soldado, diez pesos mensuales. Estos salarios representan un aumento de sueldo respecto de las reglamentaciones de 1753, según estas, un tambor en Chiloé cobraba seis pesos y cuatro reales al mes (Pérez 2018b: 58).

Unos años más tarde se registra un nuevo aumento en el salario de las tropas, ya que tanto pífanos como tambores cobraban doce pesos mensuales ( 7 de noviembre de 1817, en Aravena, Ibáñez y Orellana 2017: 125). De estas fechas hay constancia acerca de la calidad de la banda musical que tenía el Batallón de Chiloé, no muy halagüeña a decir verdad: "En 1817 entró a esta ciudad el ejército que, a las órdenes de San Martín, había triunfado en Chacabuco. Aquel ejército tenía dos bandas de música, superiores a la única que tenían los realistas en el Batallón Chiloé, que era detestable" (Merino Montero 2006: 6-7) y diminuta (Zapiola 1974: 37).

Las revistas de Comisario entregan información referente a cinco Compañías de Infantería y una de Granaderos, todas pertenecientes al Batallón de Voluntarios de Castro.

18 ANCh, FG, V. 11; véase también Pérez 2019a: 47-88. 
Se presentan seguidamente los nombres y datos personales conocidos de aquellos empleados por tambores y pífanos en cada una de estas compañías, acompañándose la información de las fechas en que consta presente en tal calidad.

En total, veintitrés tambores (incluyendo a los tambores mayores) y nueve pífanos (de ellos, probablemente solo quince y cuatro, respectivamente, con origen en Chiloé) quienes, habiendo vivido en un tiempo convulso y peligroso, dejan su música para sus compañeros de armas, y sus datos para beneficio de la historia:

\subsection{Compañía de Granaderos del Batallón de Voluntarios de Castro}

- Vicente Obando. Tambor (1 de noviembre de 1814; 1 de diciembre de 1814; 2 de enero de 1815; 1 de febrero de 1815; 1 de marzo de 1815; 1 de abril de 1815). Deja asignados cuatro pesos a María Cárdenas (1815).

- $\quad$ Eusebio Ávila. Tambor (agregado el 22 de octubre de 1814; 1 de noviembre de 1814; 1 de diciembre de 1814; 2 de enero de 1815; 1 de febrero de 1815; de licencia el 16 de febrero de 1815).

- José Barona. Tambor (sentó plaza el 19 de febrero de 1815; 1 de marzo de 1815; 1 de abril de 1815). Es prácticamente una certeza que sea hijo del cuencano Esteban Barona (Pérez 2012: 52) y de María Dolores Triviño.

- Miguel Cárcamo. Pífano (1 de noviembre de 1814; 1 de diciembre de 1814; 2 de enero de 1815; 1 de febrero de 1815; 1 de marzo de 1815; 1 de abril de 1815). Dejó asignados seis pesos a su familia (1815). Puede tratarse del mismo Miguel Cárcamo (hijo legítimo de Pedro Cárcamo y de Francisca González), quien fue bautizado el 6 de febrero de 1786.

\subsection{Primera Compañía de Infantería del Batallón de Voluntarios de Castro}

- Marcelo García. Tambor (destinado en San Isidro el 1 de noviembre de 1814; enfermo el 1 de diciembre de 1814; de guardia en Las Mercedes el 2 de enero de 1815; enfermo el 1 de febrero de 1815; de guardia el 1 de marzo de 1815; 1 de abril de 1815).

- $\quad$ Pedro Jiménez. Tambor (1 de noviembre de 1814; 1 de diciembre de 1814; 2 de enero de 1815; 1 de febrero de 1815; pasado a la Quinta Compañía de Infantería del Batallón de Voluntarios de Castro el 21 de febrero de 1815).

- José Saavedra. Tambor (pasado el 21 de febrero de 1815, 1 de marzo de 1815; 1 de abril de 1815)

- José Vargas. Tambor (pasó a La Ligua el 8 de febrero de 1815).

- $\quad$ Felipe Vargas. Pífano (1 de noviembre de 1814; 1 de diciembre de 1814; 2 de enero de 1815; 1 de febrero de 1815; 1 de marzo de 1815; 1 de abril de 1815).

5.3. Segunda Compañía de Infantería del Batallón de Voluntarios de Castro

- $\quad$ Tomás Soria. Tambor (1 de noviembre de 1814; 1 de diciembre de 1814; 2 de enero de 1815; destinado en Concón el 1 de febrero de 1815; destinado en La Ligua el 1 de marzo de 1815; 1 de abril de 1815).

- $\quad$ Pedro Castro. Tambor (agregado el 20 de octubre de 1814; 1 de noviembre de 1814; enfermo en el hospital el 1 de diciembre de 1814; 2 de enero de 1815; 1 de febrero de 1815; recibió licencia absoluta el 19 de febrero de 1815). Acaso sea el mismo don Pedro Castro, testigo de casamiento (30 de marzo de 1840 en Achao: LMA2, foja 64).

- Pedro Quirós. Tambor (sentó plaza el 19 de febrero de 1815; 1 de marzo de 1815).

- Leonardo Rodríguez. Pífano (1 de noviembre de 1814; 1 de diciembre de 1814; 2 de enero de 1815; 1 de febrero de 1815; 1 de marzo de 1815; 1 de abril de 1815). 
- $\quad$ Eugenio Hernández. Pífano (sentó plaza el 19 de febrero de 1815; 1 de marzo de $1815 ; 1$ de abril de 1815). Parece tratarse de José Eugenio Hernández (natural de Curaco; hijo legítimo de Juan Ángel Hernández y María Teresa Yáñez; casado el 2 de mayo de 1838 con María Rosario Bustamante, natural de Curaco, hija natural de Feliciano Bustamante y de María: LMA2, fojas $50 \mathrm{v})$.

\subsection{Tercera Compañía de Infantería del Batallón de Voluntarios de Castro}

- José María Pérez. Tambor (1 de noviembre de 1814; 1 de diciembre de 1814; 2 de enero de 1815; destinado en La Ligua el 1 de febrero de 1815; 1 de marzo de 1815; a bordo en La Sebastiana el 1 de abril de 1815).

- $\quad$ Pedro Tenorio. Tambor (1 de noviembre de 1814) y pífano (1 de diciembre de 1814; 2 de enero de 1815; 1 de febrero de 1815; en Chile el 1 de marzo de 1815; en Santiago el 1 de abril de 1815). Ha de ser sin duda el mismo Pedro Tenorio (hijo legítimo de Cipriano Tenorio y de Juana Uribe) quien fue casado el 26 de agosto de 1817 con Jacinta Uribe (hija legítima de José Uribe y de Josefa Torres), dispensados de sus impedimentos.

- Manuel Adriaga, Manuel Madriago o Manuel Madriaga. Tambor (agregado el 2 de noviembre de 1814; 1 de diciembre de 1814; 2 de enero de 1815; 1 de febrero de 1815; 1 de marzo de 1815; 1 de abril de 1815).

- $\quad$ Andrés Moraga. Pífano (desertó el 16 de octubre de 1814).

5.5. Cuarta Compañía de Infantería del Batallón de Voluntarios de Castro

- $\quad$ Pedro Vidal. Tambor (1 de noviembre de 1814; 1 de diciembre de 1814; 2 de enero de 1815; 1 de febrero de 1815; 1 de marzo de 1815; 1 de abril de 1815).

- Juan Ángel Ibáñez. Tambor (1 de noviembre de 1814; enfermo el 1 de diciembre de 1814; 2 de enero de 1815; 1 de febrero de 1815; pasado a soldado de la misma Compañía el 6 de febrero de $1815)$.

- José Vargas. Tambor (agregado el 18 de febrero de 1815; 1 de marzo de 1815; 1 de abril de 1815).

- José María Mardones. Tambor (agregado el 19 de febrero de 1815; 1 de marzo de 1815; desertó el 28 de marzo de 1815).

- Juan Vicente Saavedra. Tambor (agregado el 19 de febrero de 1815; 1 de marzo de 1815; 1 de abril de 1815).

- $\quad$ Tomás Contreras. Pífano (1 de noviembre de 1814; 1 de diciembre de 1814; 2 de enero de 1815; destinado en La Ligua el 1 de febrero de 1815; destinado en La Ligua el 1 de marzo de 1815; desertó el 25 de marzo de 1815).

\subsection{Quinta Compañía de Infantería del Batallón de Voluntarios de Castro}

- $\quad$ Gregorio Mansilla. Tambor (1 de noviembre de 1814; 1 de diciembre de 1814; 2 de enero de 1815; destacado en La Ligua el 1 de febrero de 1815; destinado en La Ligua el 1 de marzo de 1815; de guardia en Las Mercedes el 1 de abril de 1815).

- $\quad$ Francisco Flores. Tambor (1 de noviembre de 1814; 1 de diciembre de 1814; 2 de enero de 1815; 1 de febrero de 1815; 1 de marzo de 1815; 1 de abril de 1815). Probablemente se trate del mismo Francisco Javier Flores, llamado usualmente Francisco Flores. Natural de Rilán; hijo legítimo de José Flores y de Josefa Miranda; bautizado el 28 de mayo de 1776. Casado con Rosa Cárdenas (natural de la capilla de Aldachilu; hija legítima de Juan Ignacio Cárdenas y de Agustina Alvarado) el 12 de agosto de 1811 en la iglesia parroquial de Castro (LMC7, fojas 133).

- $\quad$ Pedro Jiménez. Tambor (pasado el 19 de febrero de 1815; 1 de marzo de 1815; 1 de abril de 1815). 
- Santiago Miranda. Tambor (pasado el 19 de febrero de 1815; 1 de marzo de 1815; 1 de abril de $1815)$.

- Felipe Vargas. Pífano (noviembre de 1814).

- José María Ceballos. Pífano (agregado el 1 de enero de 1815; 1 de febrero de 1815; 1 de marzo de 1815; 1 de abril de 1815). Probablemente se trate de un hijo de don Manuel Francisco Ceballos (natural de Lima; soldado de Asamblea; hijo legítimo de Bernardino Ceballos y de María de Leyba, AGS, SG 7103,23) y de doña Josefa Loayza.

- Rosauro Rodríguez. Pífano (pasado el 19 de febrero de 1815; 1 de marzo de 1815; 1 de abril de $1815)$.

5.7. Batallón de Voluntarios de Castro, sin mención de Compañía (Aravena, Ibáñez y Orellana 2017: 125)

- Felipe Pérez. Tambor, con sueldo de doce pesos (7 de noviembre de 1817).

- José Ribera. Pífano, con sueldo de doce pesos (7 de noviembre de 1817).

$\mathrm{Al}$ analizar la información en estos elencos, se puede mencionar a un tambor con indudable origen peruano (Manuel Hospina), pero prácticamente el $61 \%$ de los tambores y pífanos corresponden a personas con apellidos propios de la geografía de Chiloé. En cambio, apellidos como Ávila, Castro, Jiménez, Madariaga, Mardones, Quirós, Saavedra, Sicardo o Soria, no se encuentran presentes en la documentación parroquial chilota. Por ello se concluye que se trata de personas reclutadas fuera de la geografía insular, precisamente a instancias de la resistencia ofrecida a las fuerzas republicanas en la guerra de emancipación, y por ello con mucha probabilidad se trata de personas procedentes de las ciudades chilenas continentales, donde se reunían y reagrupaban las fuerzas realistas (por ejemplo, Valparaíso).

La identificación genealógica de algunas personas (como en los casos de José Vargas o Felipe Vargas, Santiago Miranda, José María Pérez, etc.) se dificulta un poco debido a la homonimia, costumbre muy difundida en Chiloé.

Los casos relevados en el período exponen nueve pífanos, lo que representa casi el $26 \%$ de las personas investigadas. Este oficio, por tanto, no era tan difundido como el de tambor.

Resulta significativo constatar que, así como recogen las leyes militares, se observa el ascenso de un tambor a tambor mayor (Manuel Hospina), pero también de tambor mayor a sargento segundo (Juan Felipe Sicardo), lo que ratifica que la carrera de las armas ofrecía a sus empleados la posibilidad de mejorar en sus capacidades y sueldos.

\section{PROYECCIONES}

El estudio de la cultura musical isleña se ha enfocado principalmente en la preservación y difusión de la música de tradición oral. Sin embargo, la recuperación del patrimonio musical de Chiloé en su conjunto puede (y debiera) acometerse desde distintos planos, con el objeto de integrar los distintos conocimientos que se relacionen con el mismo. Una obra de este alcance y estilo no existe todavía para Chiloé.

Parte de estos otros aspectos que normalmente no son valorados para un estudio tan particular, lo representan los datos dispersos en distintos tipos de archivos: documentación parroquial usual (libros de bautismos, defunciones y matrimonios) y documentación militar (como listas de revista), a las que deben sumarse las noticias de viajeros, navegantes y exploradores. Otras informaciones de interés podrían localizarse en archivos eclesiásticos o militares peruanos y españoles.

Resulta interesante considerar que la cultura histórica y social de la antigua provincia del Chiloé hispánico también comprendía territorios que han quedado desvinculados del mismo según las actuales divisiones administrativas de Chile. Es el caso de Calbuco, Maullín o Carelmapu, lugares que comparten tradiciones, relaciones familiares y constituyen parte de la herencia de Chiloé, y es probable que el análisis de informaciones de estos lugares pueda contribuir a un conocimiento más integral de la cuestión. 
La realización futura de un estudio musical pormenorizado de Chiloé desde una perspectiva militar puede plantear otras interrogantes. El origen y extracción social de los sujetos que ejecutaban la música, la formación en sus oficios, su rol en la sociedad fuera del ámbito militar y en definitiva su devenir histórico, pueden ser facetas relevantes de investigarse y aportar así a una comprensión más cabal de la dimensión sociocultural en esta localidad.

\section{BIBLIOGRAFÍA}

Aravena, Gonzalo, Ignacio Ibáñez y Alejandro Orellana

2017 Huellas de Chiloé en Lima, 1808-1824. Fuentes para el estudio de Chiloé en la Independencia. Santiago (Chile): HC, Historia Chilena: CERCH, Centro de Estudios de la Realidad Chilota.

Barría Casanova, Jaime

2014 Música en Chiloé. Puerto Montt (Chile): Bordemar.

BLANCKLEy, EDWARD

1834 "Account of the Island and Province of Chiloè: Extracted from the Remark Book Kept on Board H.M.S. Pylades 1834”, The Journal of the Royal Geographical Society of London, 4. Londres: Royal Geographical Society, pp. 344-361.

Bonaparte, José I (REY DE EsPaÑa)

1811 Instrucción para la Milicia cívica del Reino. Madrid: Imprenta Real.

BYron, JoHN

1768 The narrative of the Honourable John Byron (Commodore in a Late Expedition round the World) containing an account of the great distresses Suffered by Himself and His Companions on the coast of Patagonia, from the year 1740, till their arrival in England, 1746.: With a description of St. Jago de Chili, and the Manners and Customs of the Inhabitants. Also a Relation of the Loss of the WAGER Man of War, One of Admiral Anson's Squadron. Londres: S. Baker and G. Leigh, and T. Davies.

Carlos III (Rey de España), Don

1768 Ordenanzas de S. M. para el régimen, disciplina, subordinación y servicio de sus exercitos, tomos I y II. Madrid: Pedro Marín.

Cavada, Francisco Javier

1914 Chiloé y los chilotes. Santiago (Chile): Imprenta Universitaria.

Colón de LARriátegui, Félix

1817 Juzgados militares de España y sus Indias, tomo IV. Madrid: Ibarra, impresor de Cámara de S. M.

Ejército de Chile

1983 Historia del Ejército de Chile, Tomo I. Santiago (Chile): Estado Mayor General del Ejército.

Garrido, Waldo, Dan Bendrup y Philip Hayward

2019 Música de Chiloé. Folklore, Syncretism, and Cultural Development in a Chilean Aquapelago. Maryland: Lexington Books.

Gobierno de Chile

1866 Censo jeneral de la República de Chile levantado el 19 de abril de 1865. Santiago (Chile): Imprenta Nacional.

1876 Quinto censo general de la población de Chile levantado el 19 de abril de 1875 i compilado por la Oficina Central de Estadistica en Santiago. Valparaíso (Chile): Imprenta del Mercurio.

$1890 \quad$ Sesto censo general de la población de Chile levantado el 26 de noviembre de 1885 y compilado por la Oficina Central de Estadística en Santiago, tomo II. Valparaíso (Chile): Imprenta de La Patria.

Gómez Pérez, Carmen

1993 "La recluta en el ejército de América", A portaciones militares a la cultura, arte y ciencia en el siglo XVIII hispanoamericano. Actas de las I Jornadas Nacionales de Historia Militar, "Cátedra General 
Castaños”. Sevilla (España): Capitanía General de la Región Militar Sur, Real Maestranza de Caballería de Sevilla.

González Coll, María Mercedes

1999 "La pedagogía misionera jesuítica en dos centros de evangelización en América: Paraguay y Chiloé. Intento de un análisis comparative”, Viejos y nuevos estudios etnohistóricos: relaciones interétnicas y la emergencia de una cultura mestiza en América del Sur. María Mercedes González Coll (compiladora). Bahía Blanca: Universidad Nacional del Sur.

González Montero de Espinosa, Marisa

1992 La ilustración y el hombre americano. Descripciones etnológicas de la expedición Malaspina. Madrid: Consejo Superior de Investigaciones Científicas.

HANISCH, WALTER

1982 Chiloé, capitana de las rutas australes. Santiago (Chile): Academia Superior de Ciencias Pedagógicas de Santiago.

LATCHAM, RICARDO R.

1924 La organización social y las creencias religiosas de los antiguos araucanos. Santiago (Chile): Imprenta Cervantes.

Lavín, Carlos

1952 "La música sacra de Chiloé”, Revista Musical Chilena, VIII/43, pp. 76-82.

León León, Marco Antonio

1999 La cultura de la muerte en Chiloé. Santiago (Chile): Dirección de Bibliotecas, Archivos y Museos.

LOCKHart, Carlos

1952 El mundo hispánico-peruano. 1532- 1560, México: Fondo de Cultura Económica.

Medina, José Toribio

1882 Los aborijenes de Chile. Santiago (Chile): Imprenta Gutenberg.

Merino Montero, Luis

2006 "La Sociedad Filarmónica de 1826 y los inicios de la actividad de conciertos públicos en la sociedad civil de Chile hacia 1830", Revista Musical Chilena, LX/206, pp. 5-27, doi: http:// dx.doi.org/10.4067/S0716-27902006000200001

Milla Batres, Carlos

1986 Diccionario histórico y biográfico del Perú s. XV-XX, tomo 1. Lima: Editorial Milla Batres.

Moreno Jeria, Rodrigo

2007 Misiones en Chile austral: los jesuitas en Chiloé. 1608-1768. Sevilla: Consejo Superior de Investigaciones Científicas, Universidad de Sevilla, Diputación de Sevilla.

Morrell, BenJAmin

1832 A narrative of four voyages, to the South sea, north and south Pacific ocean, Chinese Sea, Ethiopic and Southern Atlantic Ocean, Indian and Antarctic Ocean. From the year 1821 to 1831. Nueva York: J. \& J. Harper.

Olivares, P. Miguel de

1874 "Historia de la Compañía de Jesús en Chile (1593-1736)", Colección de Historiadores de Chile y de documentos relativos a la Historia Nacional, tomo VII. Santiago (Chile): Imprenta Andrés Bello.

Ovalle, P. Alonso de

$1646 \quad$ Histórica relación del reyno de Chile. Roma: Francisco Caballo.

OYA, Francisco DE

1732 Tratado de las leyes penales de la milicia española, processos, y consejos de guerra, con notables resoluciones de Su Magestad, y advertencias para todo Oficial, y Soldado de Infanteria, Cavalleria, y Dragones, 
Guardias de Infanteria, Artilleros, y Invalidos, y para Juezes Ordinarios, y Militares. Madrid: en casa de Juan Muñoz.

Pereira Salas, Eugenio

1941 Los orígenes del arte musical en Chile. Santiago (Chile): Ediciones de la Universidad de Chile.

Pérez, Pablo A.

2012 "Nómina y genealogía de extranjeros del Ecuador presentes en Chiloé (1700-1900)", Spondylus. Revista cultural, 31, pp. 47-56.

2018a “Nómina y genealogía de extranjeros del Perú presentes en Chiloé (1700-1900)”, Revista del Instituto Peruano de Investigaciones Genealógicas, 27, pp. 445-499.

2018b "Las milicias de tierra de Chiloé, su ubicación, composición y sueldos (1753)", Fuego y Raya. Revista semestral hispano-americana de historia y política, VII/15, pp. 53-67.

2019a "Listas de revista del Batallón de Voluntarios de Castro (de noviembre de 1814 a abril de 1815)”, Cuadernos de genealogía e historia de la antigua provincia de Nueva Galicia (Chiloé), III/3, pp. $47-88$.

2019b "Nómina y genealogía de extranjeros del Santiago de Chile presentes en Chiloé (1700-1900)", Revista de Estudios Históricos, LXXI/61, pp. 247-310.

2020 "Sobre los dragones en el Ejército Real de Chiloé". Manuscrito inédito.

Pizarro, Gabriela

1991 Romances cantados. Casete. Colección de Música Chilena, Serie Música vernácula (CMCH01). Facultad de Artes de la Universidad de Chile, Sección Musicología.

Plath, Oreste

1973 Arte tradicional de Chiloé. Santiago (Chile): Museo de Arte Popular Americano.

Quevedo, María IsABel

$2006 Y$ Y las manos tejen avemarias. El rosario cantado en los novenarios de Puchaurán. Santiago (Chile): Universidad de Chile, Facultad de Artes.

Real ACADEmia Española

1737 Diccionario de Autoridades. Tomo V.

RETAMAL, FERnANDO

1983 El primer sínodo chileno de la Epoca Republicana: Ancud 1851. Santiago (Chile): Ediciones Universidad Católica de Chile, Facultad de Teología.

Rondón Sepúlveda, Víctor M.

1997 "Música jesuita en Chile en los siglos XVII y XVIII: primera aproximación”, Revista Musical Chilena, LI/188, pp. 7-39.

2009 "Jesuitas, música y cultura en el Chile colonial". Tesis para optar al grado de doctor en Historia. Santiago (Chile): Pontificia Universidad Católica de Chile.

2014 "Música y negritud en Chile: De la ausencia presente a la presencia ausente", Latin America Music Review, XXXV/1, pp. 50-87.

Salinas Campos, Maximiliano

$2000 \quad$ “Toquen flautas y tambores!: una historia social de la música desde las culturas populares en Chile, siglos XVI-XX”, Revista Musical Chilena, LIV/193, pp. 47-82, doi: http://dx.doi. org/10.4067/S0716-27902000019300003

SANZ, RAIMUNDO

1749 Diccionario militar, o recoleccion alphabetica de todos los terminos propios al Arte de la Guerra. Explicacion, y practica de los trabajos que sirven al Ataque, y Defensa de las Plazas: Sus ventajas, y defectos; segun sus diferentes situaciones; con un detalle Historico del origen; y naturaleza de diferentes especies; tanto de Empleos antiguos, y modernos; como de las Armas que se han usado en diferentes tiempos de la Monarchia francesa, hasta oy. BREVE, Y EXTRACTA EXPLICACION de la obligacion 
de los Oficiales de Infanteria, Cavalleria, Dragones, Artilleria, ̀̀ Ingenieros; sea en Guarnicion; ò Campaña, segun el methodo presente de hacer la Guerra. Barcelona: Juan Piferrer.

Urbina Burgos, Rodolfo

1983 La periferia meridional indiana. Chiloé en el siglo XVIII. Valparaíso (Chile): Ediciones Universitarias de Valparaíso.

2013 Gobierno y sociedad en Chiloé colonial. Valparaíso (Chile): Instituto de Historia, Pontificia Universidad Católica de Valparaíso.

Urbina Carrasco, María Ximena

2008 "La 'Tierra firme de Carelmapu' o área continental norte en la jurisdicción de Chiloé en el período colonial”, ¿Adónde se fue mi Gente? Memorias y realidades en la construcción de Chiloé. Esteban Barruel, Sandra Hernández Sandoval, Sergio Mansilla Torres, José Ulloa Cortés y María Ximena Urbina Carrasco (editores). Osorno (Chile): Editorial Universitaria de Los Lagos, pp, 21-42.

ZAPIOLA, José

1974 Recuerdos de treinta años. Santiago (Chile): Zig-Zag.

Fuentes primarias

AGS, SG 7093,23: Archivo General de Simancas. Secretaría de Guerra, Legajo 7093,23. "Ejército de Buenos Aires y Lima. Gratificaciones”. 1780-1788.

AGS, SG 7099,30: Archivo General de Simancas. Secretaría de Guerra, Legajo 7099,30. “Guarnición de Chiloé. Premios. Inválidos”. 1792.

AGS, SG 7103,23: Archivo General de Simancas. Secretaría de Guerra, Legajo 7103,23. "Compañías Veteranas dela Dotacion de Chiloé". 1795.

AGS, SG 7110,23: Archivo General de Simancas. Secretaría de Guerra, Legajo 7110,23. “Cuerpos de Lima y Chiloé. Premios. Estados de Fuerza". 1798.

AGS, SG 7111,17: Archivo General de Simancas. Secretaría de Guerra, Legajo 7111,17. "Tropas de Perú. Premios. Inválidos. Estados de fuerza”. 1800.

AGS, SG 7113,15: Archivo General de Simancas. Secretaría de Guerra, Legajo 7113,15. "Tropa de Chiloé. Estado de fuerza. Premios. Inválidos”. 1800.

AGS, SG 7133,1: Archivo General de Simancas. Secretaría de Guerra, Legajo 7133,1. "Regimientos y Milicias de Perú. Revistas”. 1799.

ANCh, FG, V. 11: Archivo Nacional de Chile. Fondo de Guerra, Volumen 11. "Comisaría del Ejército Real 1814-16".

LBC12: Portada: "Libro de Bautismos= / Correspondientes â las Cave / ceras de éste Curato, de / Santiago de Castro. / Añode 1799=”. Tapa: "LIBRO / de la Parroquia de Sant de / Castro [ilegible] Chiloe / [ilegible] bap[tizos] / [ilegible] Venegas / y Goyzueta. / [ilegible] de Cabecer[a] / [de] esta $p a[\mathrm{rr}]$ oq[uia] / Fray An[ilegible]"; y, sobre esto, un cartel manuscrito que dice: "Libro de / 12 / Bautismos. / 1799-1810.”. Sin leyenda en el lomo.

LDC5: Portada: "Libro de Entierros de esta Cavecera que / empieza en 2.de octubre de1817\# años\# / [papel en blanco, pegado, que dice:] timio el Vicario Cura de Esta Parrq. ${ }^{a} / 1^{\circ}$ de Maro año de 1826 a fojas 78 / 1817. 1826". Tapa: "Entierro 1817 a 1826 // [centrado:] Entierros n 5 / [papel en blanco, pegado, en cuya parte superior derecha dice:] $N^{\circ} 5$ / Libro de Entierros. / $1817 \_1826$ / $N^{\circ}$ 5". Lomo: sin leyenda.

LDT3: Portada: "Partidas / de / Muertos. / Año 1865. / 1873 // 21-1-1865 á 4-10-1873-". Tapa: "III / Libro3. ${ }^{\circ}$ de entie $=/$ rros. / $1865_{-}{ }^{\circ}$. Alojado en la Iglesia de Dalcahue. 
LMC4: En la portada dice: "Libro en que se a Sientan los Ca / Samientos de los Españoles. el qual / Corre desde

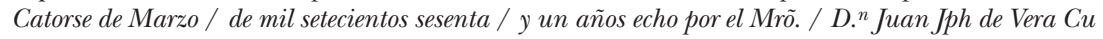
/ ra Rector y Vicario actual / que es de Esta Santa Ygle / cia de Nrã. Señora de / las Nieves siendo Go / vernadr. del Obispado / el S. or D. ${ }^{r}$ D. ${ }^{n}$ Juan / de Gusman y Peral / ta dean de dha. / Santa Yglecia / Año. de 1761; / (con otra grafía:) Año del 1761”, cada renglón centrado. En la tapa dice "LIBRO / DE CASAMIENTOS"; y, en un retazo de papel pegado puede leerse: "Lib[ro de ] / C [asamien ] tos / 176[1-179] O", y arriba a la derecha: " $N^{\circ} 4$ ". La portada debe contarse como fojas 1, mientras que la 1v se encuentra en blanco; y hay un error de numeración, ya que la fojas 128 no existe, en vez de la cual está la número 130, numeración que se sigue. Alojado en el Obispado de Ancud.

LMC7: Tapa: "LIBRO / Dela Parroquia de Sant. ${ }^{\circ}$ de / Castro enla Prov. ${ }^{a}$ deChiloé / al Cargo de su Cura Propi[e-] / tario D. ${ }^{n}$ Fran. ${ }^{c o}$ Xav. ${ }^{r}$ Vene[gas] / [ilegible] ta. / Casa[miento] sde el / [Mar]zo [de] / 1803"; todo sobre lo cual se encuentra un papel blanco pegado, donde hay manuscrito en cursiva: "Libro de $7^{\circ} /$ Casamiento[s] / 1803_[1815]". La fojas 154 no existe, en vez de las cual existe la 155 , que es la numeración que se sigue; y lo mismo sucede con la 190 que no existe, en vez de la cual sigue la 191. Alojado en la Iglesia de Castro.

LMCa3: Portada: "Libro en que se asientan las / partid.s de Casamient.s y velacion.s / hecho p.r el Lisenciado Cura Vicario / del Fuerte de S. ${ }^{n}$ Miguel de Calvu / co D. ${ }^{n}$ Ramon Camilo de Lorca / de españoles y Yndios". Una fojas antes se encuentra impreso lo siguiente: "Archivo / DE LA / Secretaría Episcopal / de Puerto Montt / DEP. Calbuco No 3 / 1794-1816 / Libro de Matrimonios / Casamientos de Españoles / e Indios". Las fojas 131 y 131v están perdidas.

LMT1: Portada: "Libro que, se Sien_ / tan las partidas / de Casamientos que em_ / piensa en $1^{\circ}$ de Eenero / de 1838. Cabesera de Tenaun.", y más arriba dice, en la misma portada: "Libro - 1". La fojas 70 no existe, y en vez de ella aparece la 80 , de donde recomienza la numeración. Además, entre las fojas 18v y 19 hay una sin numerar. Alojado en la Iglesia de Dalcahue.

LMV1: Tapa: En un papel pegado, manuscrito: "B. I- 1. / Libro Primero / de / Matrimonios / 1770 1801". Portada: "Libro de Casam. ${ }^{\text {tos }}$ / DE LA PARROQL DE VALDIVIA / corre desde doze de Julio, q. ${ }^{e}$ / se consumiò el Archivo en / el incendio de esta Yglesia. / AÑO. DE 1770. / siendo Cura Vicario / El Dr. ${ }^{\mathrm{n}} \mathrm{Jph}$. Ygn. ${ }^{\circ}$ de Rocha"; sello oval que dice: "PARROQUIA DE N.S. DEL ROSARIO / Y VICARIA FORANEA / DE VALDIVIA". Alojado en el Obispado de Valdivia. 